B. Энхчимэг, У. Нандин-эрдэнэ, А. Гоомарал. Размножение Larix Sibirica Ledeb. в культуре in vitro через соматический эмбриогенез и влияние микоризы на их рост в почве

Научная статья

УДК 58.085

DOI: $10.18101 / 2542-0623-2020-3 / 4-77-83$

\title{
PАЗМНОЖЕНИЕ LARIX SIBIRICA LEDEB. В КУЛЬTУРE IN VITRO ЧЕРЕЗ СОМАТИЧЕСКИЙ ЭМБРИОГЕНЕЗ И ВЛИЯНИЕ МИКОРИЗЫ НА ИХ РОСТ В ПОЧВЕ
}

\section{В. Энхчимэг, У. Нандин-эрдэнэ, А. Гоомарал}

\section{(C) Ванжилдорж Энхчимэг}

доктор, профессор кафедры биотехнологии и селекции, Монгольский государственный аграрный университет

Монголия, г. Улан-Батор, Зайсан 17024

enkhchimeg.v@muls.edu.mn

(C) Ундарьяа Нандин-эрдэнэ

магистрант,

Монгольский государственный аграрный университет

Монголия, г. Улан-Батор, Зайсан 17024

\section{(C) Алтансух Гоомарал}

доктор кафедры биотехнологии и селекции,

Монгольский государственный аграрный университет

Монголия, г. Улан-Батор, Зайсан 17024

goomaral@muls.edu.mn

Аннотация. В статье приведены результаты анализа размножения Larix sibirica Ledeb. в культуре in vitro через соматический эмбриогенез и влияние микоризы на их рост в почвенной среде. На основе метода показано, что для получения микроклональной лиственницы сибирской эффективно использовать в качестве регуляторов роста 1 мг/л 2,4-Д (2,4-дихлорфеноксиуксусную кислоту) и 2 мг/л 6-БАП (6-бензиламиноперемедин) с показателем среды рН-5,8. Дозировка для приготовления микоризы в соответствии с инструкциями производителя составляла 3,25 мл с добавлением 15 мл воды. У микроклональных растений, которые были заражены микоризой, боковые корни образовывались из основных корней растений, и среднее число разветвленных корней у 15 растений составляло 8,8 см. Средняя длина основного корня была на 6,7 см и на 3,4 см больше, чем у растений, которые не были заражены микоризой. Процент выживаемости микроклональных растений составлял 64. Таким образом, микоризы увеличивают количество поглощаемой воды и питательных веществ у корня растения и создают связь между корнями и почвой, разветвляя корни растений на более широкой территории.

Ключевые слова: in vitro; питательная среда MSGM; соматический эмбриогенез; лиственница сибирская; микроклональные растения; микориза.

\section{Для цитирования}

Энхчимэг В., Нандин-эрдэнэ У., Гоомарал A. Размножение Larix Sibirica Ledeb. в культуре in vitro через соматический эмбриогенез и влияние микоризы на их рост в почве // Природа Внутренней Азии. Nature of Inner Asia. 2020. № 3/4(15). С. 77-83.

DOI: $10.18101 / 2542-0623-2020-3 / 4-77-83$ 


\section{Введение}

Леса Монголии занимают переходную полосу между горно-таежными лесами Сибири и пустынями Центральной Азии и сосредоточены главным образом в горных районах на севере и западе страны. Это лесные массивы по северным склонам Хангая и Хэнтэя. С точки зрения вида и видового состава древесные растения в стране составляют лиственница - 78,7\%, кедр - 9,3\%, береза - 6,1\%, сосна $-5,0 \%$, ель $-0,23 \%$, пихта $-0,02 \%$, тополь $-0,2 \%$, осина $-0,05 \%$, вяз $-0,01 \%$, ива $-0,28 \%$ и саксаул $-0,15 \%{ }^{1}$. Лиственница сибирская (Larix sibirica Ledeb.) - один из наиболее распространенных и важнейших лесообразующих видов рода Larix. В мире насчитывается более 20 видов лиственницы, а в Монголии произрастают три вида лиственницы: Larix sibirica Ledeb, Larix sukaczewii и Larix gmelinii. Это самые распространенные деревья в лесу, занимающие более 70\% [Дугаржав Ч., 2006]. Лесная экосистема страны сильно пострадала от деятельности человека, технологии лесозаготовок. В дополнение к вышеперечисленным факторам это зависит от биологических характеристик дерева, климатических условий, засухи, а также воздействия болезней и вредителей [Цогт 3., 2012, Доржсурэн Ч., 2009]. Например, когда семена лиственницы прорастают, корневая шейка высыхает, основной стебель разлагается и $60-70 \%$ семян лиственницы становятся недееспособными из-за грибковых заболеваний и насекомых.

Соматический эмбриогенез является перспективным направлением в создании сортового плантационного лесовыращивания. В Монголии был разработан зиготический эмбриогенез Larix sibirica Ledeb у лиственницы сибирской в 2015 г. [Даваажаргал М., 2015]. Размножение larix sibirica ledeb. в культуре in vitro через соматический эмбриогенез и влияние микоризы на их рост в почвенной среде изучено недостаточно. При микроклональном размножении наблюдаются большие потери растений на этапе пересадки в другие условия. Приживаемость к новым условиям зависит от субстрата. Установлено, что для пробирочных растений необходим субстрат объемом пор $25 \%$ [Kim, 1988]. Большую роль в приживаемости растений к новым почвенным условиям играет его фитосанитарное состояние. Обогащение субстрата микоризой увеличивало приживаемость и рост растений [Чекурова Г. В., 1990]. Таким образом, растения, которые высаживают в другую почву, должны адаптироваться к новым условиям.

\section{Объекты и методы исследования}

В качестве материала для исследований использовались семена, собранные в 2017 г. с Биндер сум Хэнтийского аймака. Координаты GPS: N 48020'54,9"; Е $108^{\circ} 40^{\prime} 07,0$, высота над уровнем моря 1578 м. Собранные семена имели ширину - 1,5-1,7 мм, длину - 3,5-5 мм, от темно-коричневого до желтоватого цвета. Очищенные семена замачивают в дистиллированной воде в течение 24 часов, обрабатывают раствором 70\%-ным этанолом в течение 1 минуты. Затем семена стерилизовали в течение 15 минут раствором, содержащим 2,5\% гипохлорита натрия $(\mathrm{NaOCI})$, и тщательно промыли дистиллированной водой.

Питательная среда готовится заранее. Готовят базовую среду, включающую микро- и макроэлементы, витамины, железо, органические вещества в заданном количественном содержании компонентов в соответствующей модификации

${ }^{1}$ Report on State of the Environment of Mongolia, 2017-2018. 
В. Энхчимэг, У. Нандин-эрдэнэ, А. Гоомарал. Размножение Larix Sibirica Ledeb. в культуре in vitro через соматический эмбриогенез и влияние микоризы на их рост в почве

состава среды по MSGM. В качестве регуляторов роста использовали 1 мг/л 2,4-Д (2,4-дихлорфеноксиуксусную кислоту) и 2 мг/л 6-БАП (6-бензиламиноперемедин). Водородный показатель среды доводили до 5,8 перед автоклавированием. Проводится автоклавирование при $121^{\circ} \mathrm{C}, 110$ кРа в течение 20 минут. В полученную среду вводят экспланты зародышей семян. В каждой чашке Петри культивируют по 5 зародышей на 20 мл индукционной среды в темноте при $25 \pm 2^{\circ} \mathrm{C}$.

Микоризный субстрат для увеличения приживаемости и роста растений. Культивируемые in vitro микроклональные лиственницы сибирской пересаживают в горшок с субстратом, а на корни наносят препараты микоризы, сделанные в Словакии (Symbiom). Они были использованы в исследовании и включали следующие компоненты. Эктомикориза: Amanita rubescens, Hebeloma velutipes, Paxillus involutus, Coenococcum geophilum Эндомикориза: Claroideoglomus etunicatum Claroideoglomus claroideum Rhizophagus irregularis Funneliformis geosporum Funneliformis mosseae. Дозировка для приготовления микоризы в соответствии с инструкциями производителя: эктомикориза и эндомикориза по 3,25 мл с добавлением 15 мл воды. Почву просеивали через мелкое сито и стерилизовали в автоклаве в течение 20 минут, после чего стерилизованную почву помещали в столбчатый контейнер с микоризой. 35-дневные микроклональные лиственницы сибирской пересаживали в микоризную почву. Растения поливали 10 мл воды и регулярно опрыскивали, чтобы увлажнить их. В качестве контроля использовали микроклональные лиственницы сибирской, выращенные в почвах без микоризы.

\section{Результаты исследований}

В течение 14 дней пересаженные 5 эмбрионов в один контейнер зародыши прорастают через 2-4 дня (рис. 1А). Через 7 дней образуются почки и первичные корни (рис. 1Б). Однако 35-дневные микроклональные лиственницы морфологически сходны с лиственницей из семян и готовы к пересадке в почву (рис. 1В, $1 Г)$. Тем не менее растения in vitro, особенно лиственничные микроклональные растения, имеют недостаток, заключающийся в невозможности адаптации непосредственно к внешней среде. Внешне эти растения тонкие и не закрываются края листьев, поэтому их необходимо адаптировать. Мы наполовину открыли крышку чашки Петра на 5-7 дней, накрыв пластиковым пакетом, и постепенно адаптировали к внешней среде. Перед тем как посадить в почву, корни микроклональной лиственницы промывали теплой водой, удалив питательную среду. Очищенные от питательной химической среды растения посадили в почву. В течение первой недели накрывали растения пластиковыми пакетами, чтобы предотвратить потерю влаги, и постепенно адаптировали микрорастения к внешней среде. Затем их пересаживали в почву с микоризой (рис. 1Д). Наблюдая за стадией микроклональной лиственницы сибирской, мы можем сделать вывод, что для получения лиственницы из зародышей семян требуется около 30-40 дней.

В результате у микроклональных растений, выращенных в почве без микоризы, корни не были заражены микоризой. Из основных корней растения не возникало разветвленных боковых корней (Рис $2 \mathrm{~A})$. Средний рост 15 растений составил 3,3 см, а средняя длина основного стебля - 4,3 см. Однако у микроклональных растений, которые были заражены микоризой, боковые корни образовывались из основных корней растений и среднее число разветвленных корней у 15 растений составляло 8,8 (табл. 1). 


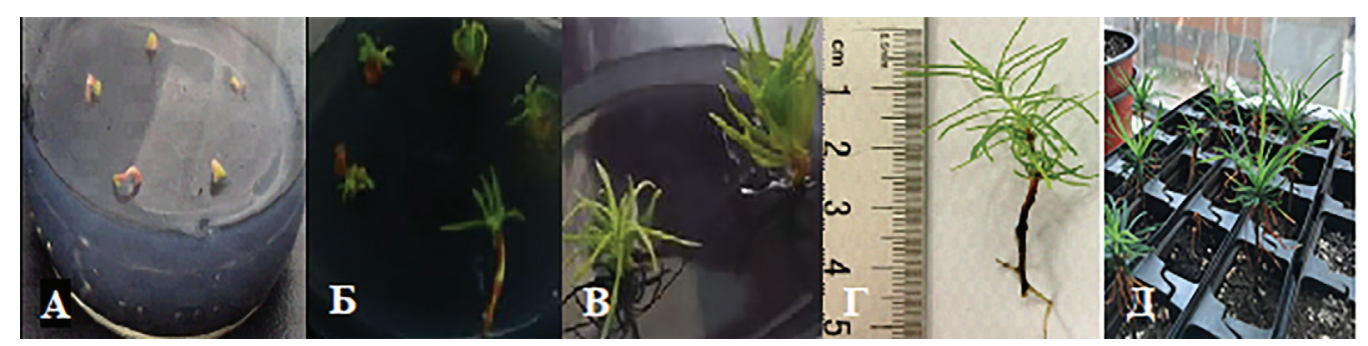

Puc. 1. А. Эмбриогенез, Б. Семидневный зародыш,

В. Микроклональное растение после 35 дней Г. 35-дневное микроклональное растение с главным корнем, Д. Растение, пересаженное в почву

Рост инфицированных микоризой корней и растений

Таблииа 1

\begin{tabular}{|c|c|c|c|c|}
\hline & $\begin{array}{c}\text { Число } \\
\text { разветвленных } \\
\text { корней,ш }\end{array}$ & $\begin{array}{c}\text { Длина } \\
\text { разветвленных } \\
\text { корней, см }\end{array}$ & Рост растений, см & $\begin{array}{c}\text { Длина главного } \\
\text { корня, см }\end{array}$ \\
\hline Без микоризы & 0 & 0 & $3,3 \pm 0,4$ & $4,3 \pm 1,3$ \\
\hline С микоризой & $8,8 \pm 4,5$ & $2,0 \pm 0,6$ & $4,4 \pm 0,8$ & $6,7 \pm 1,2$ \\
\hline
\end{tabular}

Кроме того, средняя длина разветвленных корней составляла 2 см, а средний рост растений - 4,4 см, что на 1 см выше, чем у растений, которые не были заражены микоризой, тогда как средняя длина основного корня была на 6,7 см и на 3,4 см больше, чем у растений, которые не были заражены микоризой (Рис 2Б). Микоризообразование на рис. 2В показывает, что гриб обволок корни растений.


Puc. 2. Корень лиственницы А. без микоризы. Б. с микоризой В. микоризообразование

Из этого можно сделать вывод, что заражение микоризой микроклональной лиственницы усиливает рост верхней части лиственницы и рост корней.

Коэффициент выживаемости деревьев, зараженных микоризой, определяли путем сравнения количества живых деревьев с общим количеством деревьев, выраженным как 100\%.

На рис. 3 процент выживаемости микроклональных растений после сто двацати дней составляет 64, процент выживаемости контроля составляло 42 после шестидесяти дней. Приживаемость к новым условиям контроля после шестидесятидневного роста показала неспособность выжить. 
B. Энхчимэг, У. Нандин-эрдэнэ, А. Гоомарал. Размножение Larix Sibirica Ledeb. в культуре in vitro через соматический эмбриогенез и влияние микоризы на их рост в почве

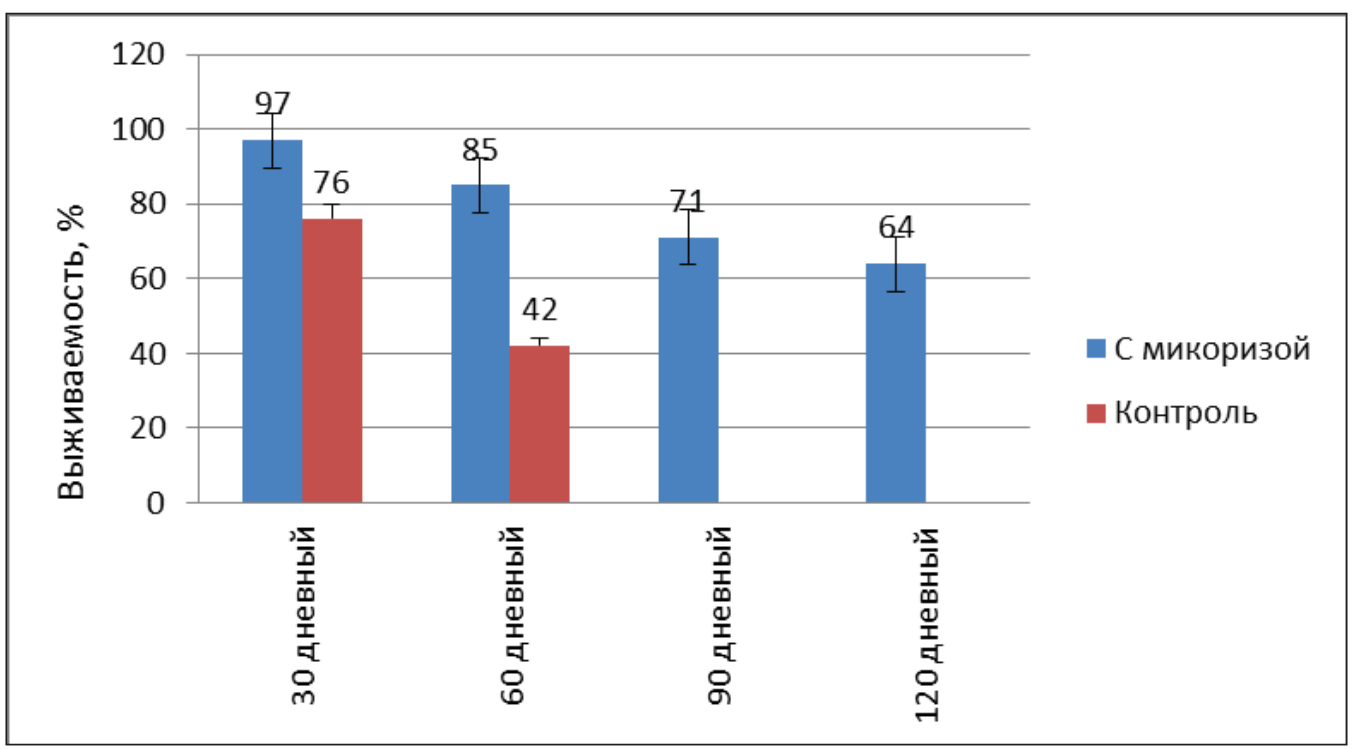

Pис. 3. Коэффициент выживаемости микроклональной растений

\section{Обсуждение}

И. Н. Третьякова, А. В. Барсукова [2012] использовали комбинацию БАП и гормонов 2.4-D в питательной среде MSGm для образования почек каллуса in vitro путем соматического эмбриогенеза из зародышей зигот лиственницы Larix sibirica, L. gmelinii и L. sukaczewii. Из зародышей трех видов лиственницы образовались 50-81\% каллуса из L. gmelinii, 53-93\% лиственницы Larix sibirica и 98\% лиственницы L. sukaczewii. В исследовании мы опирались на работу Цэрэндэжид Л., Энхчимэг В. [2019], которые объединили гормоны MSGm 2.4-D и BAP in vitro, чтобы сформировать почки из эмбриона. В Монголии использование микоризы после культуры in vitro на Larix sibirica изучено мало. Исследования Pinus sylvestris в теплицах показали, что высота проростков, диаметр шейки и длина корня определяются тем фактом, что эктомикориза ускоряет рост проростков [Гантуяа Б., Бүрэнжаргал O., 2019]. P.D. Khasa и другие [2001] изучили на проростке Larix sibirica шесть видов эктомикоризных грибов. Для лучшего роста сеянцев и улучшения качества окружающей среды снизили уровень удобрений в питомниках до $33 \%$, используя отобранные микоризные грибы. Колонизация эктомикоризы во всех проростках не зависела от уровня удобрений. Растения формировали хорошо развитую эктомикоризу. В наших исследованиях микроклональные проростки Larix sibirica Ledeb всходят с 9 видами микориз, что привело к росту корней на 6.7 см больше, чем без микоризного контроля. Таким образом мы видим, что микоризы увеличивают количество поглощаемой воды и питательных веществ у корня растения и создают связь между корнями и почвой, разветвляя корни растений на более широкой территории (Gerdemann, 1974).

\section{Заключение}

Таким образом было определено, что для получения микроклональной лиственницы сибирской эффективно использовать в качестве регуляторов роста 1 мг/л 
2,4-Д (2,4-дихлорфеноксиуксусную кислоту) и 2 мг/л 6-БАП (6-бензиламиноперемедин). У микроклональных растений, которые были заражены микоризой, боковые корни образовывались из основных корней растений и среднее число разветвленных корней у 15 растений составляло 8,8 см. Средняя длина основного корня была на 6,7 и 3,4 см больше, чем у растений, которые не были заражены микоризой. Исходя из этого видно, как микоризы увеличивают у растения корни, которые разветвляются на более широкой территории.

\section{Благодарность}

Авторы выражают огромную признательность и благодарность германской государственной компании (GIZ) за оказанную помощь в проведении данного исследования.

\section{Литература}

1. Gerdemann J. W. The Endogonaceae of the Pacific Northwest // Mycologia Memoir № 5. The Mycological Society of America, 1974. P. 38.

2. Даваажаргал М., Ариунаа М., Буянчимэг Б., Оюунбилэг Б. Разможение Larix sibirica Ledeb in vitro через зиготический эмбриогенез (на монгольском языке). Улан-Батор, 2014. $202 \mathrm{c}$.

3. Доржсурэн. Ч Антропогенные сукцессии в лиственничных лесах Монголии. Биологические ресурсы и природные условия Монголии // Тр. совместной российско-монгольской комплексной биологической экспедиции. М., 2009. Т. 50.260 с

4. Дугаржав Ч. Лиственничный лес Монголии (на монгольском языке). Улан-Батор, 2006. C. 9.

5. Khasa P. D., Sigler L., Chakravarty P., Dancik B. P., Erickson L, Curdy D. Mc Effect of Fertilization on Growth and Ectomycorrhizal Development of Container-Grown and Bare-Root Nursery Conifer Seedlings // New Forests. 2001. No. 22. P. 179-197.

6. Kim K. Wetal. Effect of ABA and Agar in Preventing Verification of Carnation Plantlets Cultured in vitro // J. of Korean Soc. for Hort. Sci, 1988. Vol. 29, № 3. P. 208-215

7. Нандинцэцэ М. Исследование факторов, влияющих на микроклональные растения Larix sibirica Ledeb in vitro. Улан-Батор, 2015. С. 3.

8. Оюунбилэг Ю., Мунхцэцэг Ц., Даваажаргал М. Растения in vitro. Улан-Батор, 2003. $44 \mathrm{c}$.

9. Tretyakova I. N., Barsuliova A. V. Somatic Embryogenesis in in vitro Culture of Three Larch Species // Russian Journal of Developmental Biology. 2012. Vol. 43, No. 6. P. 353-361.

10. Цэрэндэжид Л., Энхчимэг В. Влияние регуляторов роста на Larix sibirica Ledeb in vitro (на монгольском языке) // Mongolian Journal of Agricultural Sciences. 2019. No. 26(01). P. $108-116$.

11. Чекурова Г. В. Размножение клюквы крупноплодной в культуру in vitro // Бюлл. Г. 1990. Вып. 157. С. 90-95.

12. Цогт З., Данилин И. М. Process of Young Larch Forests Emerging Formation and Some Growth Development Characteristics in Mongolian // Proceedings of the Mongolian Academy of Science. 2012. Vol. 52. No. 3(203). P. 34-39. 
В. Энхчимэг, У. Нандин-эрдэнэ, А. Гоомарал. Размножение Larix Sibirica Ledeb. в культуре in vitro через соматический эмбриогенез и влияние микоризы на их рост в почве

\section{REGENARATION OF LARIX SIBIRICA LEDEB. IN IN VITRO CULTURE THROUGH THE SOMATIC EMBRYOGENESIS AND THE EFFECT OF MYCORHYZA ON ITS GROWTH IN SOIL}

V. Enkhchimeg, Nandin-Erdene U., Goomaral A.

Enkhchimeg Vanjildorj

$\mathrm{PhD}$, Prof. of School of Animal Science and Biotechnology

Mongolian University of Life Sciences

Zaisan 17024, Ulaanbaatar, Mongolia

enkhchimeg.v@muls.edu.mn

Undarya Nandin-Erdene

Master,

Institute of Animal Science and Biotechnology

Mongolian University of Life Sciences

Zaisan 17024, Ulaanbaatar, Mongolia

Altansukh Goomaral

$\mathrm{PhD}$,

Institute of Animal Science and Biotechnology

Mongolian University of Life Sciences

Zaisan 17024, Ulaanbaatar, Mongolia

goomaral@muls.edu.mn

Abstract. The article presents the results of the analysis of Larix sibirica Ledeb. reproduction in in vitro culture through the somatic embryogenesis and the effect of mycorrhiza on their growth in the soil environment. To obtain microclonal Siberian larch it is effective to use $1 \mathrm{mg} / \mathrm{L} \mathrm{2,4-D} \mathrm{(2,4-dichlorophenoxyacetic} \mathrm{acid)} \mathrm{and}$ $2 \mathrm{mg} / \mathrm{L}$ 6-BAP (6-benzylaminoperemedin) as growth regulators with $\mathrm{pH}-5.8$. The dosage for preparation of mycorrhiza according to the manufacturer's instructions was $3.25 \mathrm{ml}$ with the addition of $15 \mathrm{ml}$ of water. In microclonal plants that have been infected with mycorrhiza, lateral roots are formed from the main roots of the plants, and the average number of branched roots in 15 plants is $8.8 \mathrm{~cm}$. The average length of the main root is $6.7 \mathrm{~cm}$ and $3.4 \mathrm{~cm}$ longer than in plants that have not been infected with mycorrhiza. The survival rate of microclonal plants is 64. Thus, mycorrhizae increase the amount of water and nutrients absorbed by the plant root and create a connection between roots and soil, branching the plant roots over a wider area.

Keywords: in vitro; MSGM nutrient medium; somatic embryogenesis; Siberian larch; microclonal plants; mycorrhiza.

Статья поступила в редакцию 27.11.20; одобрена после редактирования 16.12.20; принята к публикации 18.12.20. 